\title{
Phenotypic Plasticity in Plant Adaptation and Coexistence
}

\author{
Kordyum E.L. , Dubyna D.V. \\ Institute of Botany, National Academy of Sciences of Ukraine, Tereschenkivska Str. 2, 01004 Kyiv, Ukraine. \\ *Corresponding Author: Kordyum E.L., Institute of Botany, National Academy of Sciences of Ukraine, \\ Tereschenkivska Str. 2, 01004 Kyiv, Ukraine.
}

\begin{abstract}
The problem how plants as a sessile organisms survive in the heterogeneous environment, changes that are often unfavorable to life, remains one of the most pressing modern biology, especially in connection with forecasts of global climate change and increased man-made pressure. We discussed the available views about numerous types of plant life strategies and mechanisms of competition and coexistence in plant communities in the light of an adaptive essence of phenotypic plasticity and its ecological significance. Autotrophic type of nutrition eliminates competition for inorganic resources as they are unlimited. On our opinion, differences in ontogenesis duration, species biological and ecological traits, reproduction systems, and sequence of seasonal development, as well as plasticity of the plant structural and functional organization in ontogenesis provide plant coexistence in modern biotopes and thus their stability.
\end{abstract}

Keywords: plasticity, adaptation, life strategy, coexistence, competition.

\section{Introduction}

Understanding the mechanisms to form the plant functional interrelations with the environment, that provides plant growth, development, reproduction, and distribution in various ecological conditions, is one of the priority problems of theoretical and experimental biology, especially under the forecast of climate global changed. The questions on stability and plasticity (phenotypic and genetic) of ontogenesis and life strategy of plants in the light of species interrelations in a cenosis are the most topical. Plants ensure the existence of mankind and all living organisms on earth by supplying oxygen to atmosphere, absorbing carbon dioxide from it and providing the necessary food. We investigated plant responses at the organism, cellular and molecular levels to the adverse changes of water regime using aerial-aquatic and true water plants grown in nature and in the experimental conditions during more 2 decades. Analysing the results of these investigations and observations of the surrounding terrestrial vegetation, we came to certain thoughts on a role of phenotypic plasticity in the individual development of plants, their adaptation to the environment and ecological interrelations. A short review of available literary data and our ideas on these questions is presented in the given paper.

\section{Phenotypic Plasticity}

The system's stability provided by the ability of its components to lability in certain limits is a paradigm of modern science. In biology, it is phenotypic plasticity, i.e. a genome competence to change its expression and form different phenotypes in response on environment fluctuations. The genetically determined ontogenesis program is under the genetic control, however, survival of organisms, in particular plants, in the heterogenic environment is stipulated by a certain plasticity of their organization in response to changes of ecological factors. This idea is based on the Shmalgausen's concept on evolution of ontogenesis [1], according to which a higher resistance of individual development occurs at the background of its variability.

Phenotypic plasticity is considered as the main mode to provide plant survival under unfavorable changes of the environment. To understand its importance in plant adaptation, population dynamics, and evolution, the wide theoretical and experimental investigations of phenotypic plasticity at the population and interspecies levels have been carried out [2-10]. It has been established that patterns of phenotypic plasticity become apparent at the level of transcription and display in numerous structural and functional traits of plant growth, development and reproduction. According to the modular concept of phenotypic plasticity, changes in expression of traits during plant growth and 
development or in response to environmental impacts occur at the level of modules [11]. Thus, plasticity of a whole organism is a manifestation of all responses of separate modules and an interrelation between them. It has been proved that phenotypic plasticity realizes in the limits of a reaction norm at the basis of metabolic and hormonal regulation of gene expression. Recently, the epigenetic system is considered to be a key in variations of plant growth and plasticity in reactions on the environmental signals, especially under stress [12-14]. Epigenetic system gains in special importance in plants, that is caused by the features of plant biology, namely: a wide distribution of vegetative reproduction, which can dominate in many perennial plants; modular organization and unlimited growth, i.e. new roots, leaves and flowers are formed during life cycle of a plant; annual formation of new shoots in trees and shrubs; the presence of such types of apomixis as apospory and adventive embryony.

It is stressed the concept on phenotypic plasticity as a general biological phenomenon requires the special attention to its ecological aspects, as the essential impact of organism plasticity on stability and local diversity of populations and cenoses is supposed $[6,15,16]$. Investigations of plasticity in the ecological aspect are important for further understanding of both the mechanisms of organism responses on the abiotic and biotic factors, and the impact of such responses on interrelations of organisms with the environment. The studies in this aspect are directly connected with existing ideas on life strategies of organisms.

\section{Types of Strategies}

The classifications of both types of strategies and life forms of plants are the most common among classifications of plant world objects [17]. A strategy type reflects a certain triad of "survival rate" an ability of the population to resist the competition and occupy either space of a niche, survive stresses caused by abiotic and biotic factors, and recover after disorders. For the first time, L.G. Ramensky [18] identified three types of "cenotic types" (types of strategies later) among plants of the same cenosis 1) lions (violents), having the highest competitive potential in the territory's capture in conditions close to a certain optimal level for them due to the energy of growth, strength and stability of the shoots; camels (patiens, tolerants), growing in different, not optimal habitat due to its endurance to various adverse conditions, and 3) jackals (explerents), quickly occupying the temporarily vacated area, and also quickly replaced by others, more competitive plants.

Almost 40 years later, J.P. Grime [19, 20] proposed three cenotic types, per se identical to those of L.G. Ramensky, introducing for their definition the term "strategy". This term has become widely used in the future. A current model of three strategies (CSR) is based on the ideas of L.G. Ramensky and J.P. Grime and includes three primary adaptive strategies of plants: 1) competitors (C), a crucial trait of which is an ability to engage resources rapidly, that maximizes vegetative growth in productive, relatively undisturbed conditions; 2) stress-tolerants (S), which are characterized by reduced vegetative and reproductive vigor and an ability to adapt in conditions of environmental stresses and severe resource depletion; and 3) ruderals (R), associated with both a short life span and an ability to use rapidly assimilated resources for high seed production in environments disturbed at the certain levels. Acceptance of $\mathrm{C}-, \mathrm{S}$ and $\mathrm{R}$-strategies does not exclude the possibility of many additional ecological variations inside every category [20]. On the meaning of L.E. Romanovsky [21], the identification of environmental factors influencing the formation either life strategy is a crucial problem of the definition and classification of strategies. A number of main primary life strategies depends on the quantity and possible combinations of such factors - determinants of strategies. B.M. Mirkin [17] introduced the notion "ecological and cenotic strategies (ECS)" considering the dual aytand syncological nature of adaptation to survival, as an expression of ways of plant survival in different ecological and cenotic conditions. On B.M. Mirkin's opinion, a type of ecologo-cenotic strategy is a phenotypic notion in the first place and represents the adaptive complex formed by a genome of the population, as a species may change its coordinates in a space of ECS types under the environmental fluctuations. Transitional types represent phenotypic variations. J.P. Grime [19] supposed "competitive, stress-tolerant, and ruderal plants seem to exhibit three quite distinct types of response to stress. It is concluded such differences constitute one of the more fundamental criteria whereby the three strategies may be distinguished".

\subsection{Life Adaptive Strategy - To Leave Offspring and Preserve a Species}

Analysing literary and our data, we concluded that different types of plant adaptive strategies (see review [20] based on the biological and ecological traits, namely: patterns of plants' habitus, duration 
of individual development (annuals, biennials, perennials), reproduction systems (sexual and vegetative, and its ratio), transition time to reproductive phase of ontogenesis, describe components of cenoses"cenotic types" only. CSR or ECS do not discover the essence of adaptation processes in a modern cenosis, since its all regular components are adapted to conditions of the existence. Under the changes of environmental factors of natural or anthropogenic origin, plants of different cenotic types reveal plasticity, similar in general terms, to adapt and survive in new conditions. Under the strategy of life (a life cycle), we understand the immanent ability of all living organisms to propagation, that is, the implementation of the "reproductive imperative" - leaving offspring and preserving a species. Therefore, the universal response of plants of different biology and ecology to adverse environmental changes is the reduction of ontogenesis, that is, the acceleration of transition from the vegetative phase to the generative leading to acceleration of ontogenesis. Variations in the sizes of plant flowering and fruiting in favorable and unfavorable condions well illustrate this idea. It should be noted that quantitative traits of vegetative and generative organs show significant plasticity with the changes in growing conditions, while the inflorescence shape and the flower size remain more or less stable.

A dramatic example may be an aerial-aquatic Alisma plantago aquatica L. species, when its achenes have been blown into the sand on the river bank. Under water restriction beginning from the early stages of seedling growth, a size of vegetative organs sharply decreased. Plants of this species, roots of which were in the soil under water, reached a height of $120-150 \mathrm{~m}$ in average. Upland plants decreased even to $10-15 \mathrm{~cm}$ in height. It is important that generative organs in aerial-aquatic and upland plants differed little in size, e.g. petal length $\mathrm{x}$ width was $7.3 \pm 02 \times 5.8 \pm 0.1 \mathrm{~mm}$ and $6.2 \pm 0.1 \mathrm{x}$ $5.5 \pm 0.2 \mathrm{~mm}$, respectively. Mass of 1000 achenes in aerial-aquatic and upland plants also similar $339.4 \pm 3.5 \mathrm{mg}$ and $316 \pm 3.2 \mathrm{mg}$, respectively [22]. It is assumed that preserving the size and shape of a flower, in particular in insect-pollinated plants, is of great adaptive importance, since deviations in flower size could adversely affect the process of pollination. On the example of Cynoglossum officinale L. populations from different sites, it was shown that any relationship between the probability of flowering and growth rate is a form of phenotypic plasticity in the threshold size of a plant for flowering [23]. A range of flexible adaptive responses of species in ontogenesis to stress at the cellular and molecular levels may vary somewhat depending on ecological peculiarities and a reaction norm genetically determined (genetic variability) of their populations. We share views of certain scientists concerning the inexpediency of using a term "strategy" due to its anthropomorphous essence to define the biological and ecological traits of species in a modern biocenosis, although it may characterize to an acceptable extent one or another direction of selection by choice of scientist.

\section{Competition or Coexistence}

"Competition and coexistence are fundamental ecological processes that affect community assembly, structure and response to disturbance" [24]. During last century, competition for resources is considered as the main factor in the formation of a life cycle strategy [19-21, 25, 26]. Summing up the concept of life cycle strategy, Yu.E. Romanovsky noted that its further development is closely linked with the development of the competition theory. In J. Weiner's opinion [27] (1993), competition is ubiquitous in its effect on plants. Plants, on which neighboring plants do not adversely affect, are rarely found.

But how then to explain the diversity and wealth of the plant world? Still G.E. Hutchinson [28] emphasized that understanding the long-term coexistence of many competing species is a longstanding central issue of the community ecology. Unlike the classical theory of competition that anticipates the exclusion of species with similar needs, modern ideas emphasize that species diversity can be explained by numerous processes of varying weight that operate at different levels. Similarities in competitive ability can often facilitate coexistence. According to L.G Ramensky [18], plants with different environmental requirements grow together in certain medium conditions, as if in compromise. "Such interpretation of the unity of plant communities based on the understanding of the ecological peculiarity of each organism is the only correct". Numerous models and theories have been later put forward to explain the coexistence of species competing for resources [24, 29, 30]. To understand competitive coexistence in a heterogeneous environment, a theory of spatial competition integrates such basic concepts as niche theory, spatial heterogeneity and spatial level or levels of coexistence [31]. The first mathematical model of coexistence of species competing for shared resources was proposed by R.A. Armstrong and R. McGehee [32]. A modern general theory of 
competitive coexistence has been mathematically formalized by P. Chesson [33]. S.P. Hubbell [34] offered a neutral theory to explain biodiversity based on the idea on ecological equivalence of trophically similar species contrary to the classical niche theory.

Since this is mainly about the coexistence of species competing for resources, let us consider what resources are needed for growth and development of plants that are sessile and differ by autotrophic type of nutrition. Plants products organic matter from water and carbon dioxide thanks to energy of sun light and a green pigment chlorophyll which is situated in cell organelles - chloroplasts, i.e. photosynthesis process. Thus, plants are the first link that combines inorganic and organic worlds and underlies the further trophic chains of heterotrophic organisms in the biosphere.

Inorganic resources needed for photosynthesis and respiration as sun light, carbon dioxide and oxygen in atmosphere are unlimited. Sunlight intensity is really different on the open area, above the canopy and under the canopy of trees. But each habitat in nature with different sunlight intensity and spectrum is occupied by plant species which the photosynthetic apparatus adapted to these conditions and works effectively. Light-requiring plants grow under bright sunshine; shade-enduring plants grow in places of varying degrees of shade. In addition, the photosynthetic appatatus is sensitive to light intensity and quickly adjusts to its fluctuations. Changes in the structure of the photosynthetic apparatus when adapted to seasonal variations in the environment, in particular lighting, were attributed by A.D. Bradshow [2] to phenotypic plasticity. Water supply depends on the moisture content in soil (the amount of precipitation), and the content of mineral substances (bioelements) varies in different soils. Water and bioelements are available to all components of the phytocenosis. Plants grow in granite slits settling by roots in the thin layer of soil and among stones in sand. Epiphytes, that is, plants, which grow on other plants, mainly get mineral substances from the surrounding environment, having aerial roots. Often it is possible to observe how house plants grow and feel well in very small pots. There are views that the formation of a large number of fruits and seeds can be one of the means of competition for the area, but it does not pay attention that in this way the plants provide food for birds and feral animals, as well as create strategic reserves of "seed" material that can be stored in soil for hundreds years. It is interesting to observe the restoration of natural flora in case of destruction of artificial covering (asphalt, various tiles, etc.) as well as the plants which are settled on the walls of buildings and fences, where there is at least a little substrate, in which they can be fixed by roots.

We came to the conclusion that coexistence of species, not competing for resources, is the main mode of complicated interrelations of plants in modern phytocenoses, which exist throughout the history of mankind. The stated views are concordant with the ideas about positive species interactions and species complementarity based on the experimental research [35-40], which facilitate the organization and productivity of plant natural communities. The existence of multispecies assemblages is considered as species complementarity that is founded on functional diversity of species (cenotic types) and positive interactions among species, "as such interactions enhance the ability of species to utilize resources" [14]. For example, inherent differences and plasticity in crown architecture in canopy space among species are discussed as one form of complementarity in plant communities, related to light interception and use and enchanced productivity in forests [40].

Coexistence (facilitation, complementarity) of plants in phytocenoses is conditioned by the biological peculiarities of cenotic types, namely by differences in life (morphological) forms and types of root systems, duration of ontogenesis, reproduction systems, sequence of seasonal development as well as the level of phenotypic plasticity in response to various, including adverse environmental changes climatic, seasonal and meteorological. Range of plasticity reflects the ecological and biological peculiarities of the species that make biocenoses, their different attitude to the environment, to each other, their dynamics or inertia. Just coexistence of species different on biology and ecology provides stability of phytocenoses and, thus, stability of the plant cover, without which life of the planet Earth is impossible.

A scheme of aut- and synecological plasticity and stability of phytocenoses may be presented by the following image (Fig. 1). 


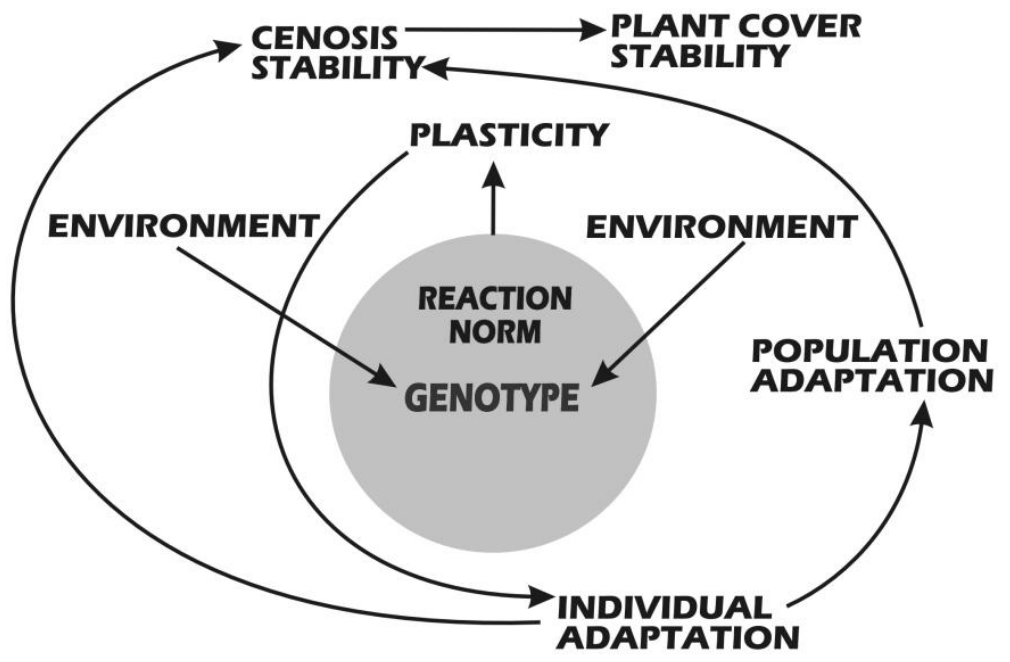

Fig1. A scheme of aut- and synecological plasticity and stability of phytocenoses

\section{REFERENCES}

[1] Shmalgausen I.I., Ways and Patterns of the Evolutionary Process, Moscow-Leningrad: Publ. House USSR Acad Sci., 1940. (In Russian)

[2] Bradshow A.D., Evolutionary significance of phenotypic plasticity in plants, Adv. Genet. 13, 115 (1965).

[3] Kuiper P.J.C., Adaptation mechanisms of green plants to environmental stress, Ann. N.Y. Acad. Sci. 851(1), 209 (1998).

[4] Sultan S.E., Phenotypic plasticity for plant development, function and life history, Trends Plant Sci. 5(12), 537 (2000).

[5] Schlichting C.D. and Smith H. phenotypic plasticity: linking molecular mechanisms with evolutionary outcomes, Evol. Ecol. 16, 189 (2002).

[6] Aubin-North N. and Renn C.P., Genomic reaction norms: using integrative biology to understand molecular mechanisms of phenotypic plasticity, Mol. Ecol. 18(18), 3763 (2009).

[7] Kelly S.A., Panhuis T.M. and Stoehr A.M., Phenotypic plasticity: molecular mechanisms and adaptive significance, Compr. Physiol. 2(2), 1417 (2012).

[8] Abakumova M., Zobel K., Lepik A. and Semchenko M., Plasticity in plant functional traits is shaped by variability in neighbourhood species composition, New Phytol. 211(2), 455 (2016).

[9] Schneider R.F. and Meyer A., How plasticity, genetic assimilation and cryptic genetic variation may contribute to adaptive radiations, Mol. Ecol. 26(1), 330 (2017).

[10] Mizutani M. and Kanaoka M.M., Environmental sensing and morphological plasticity in plants, Semin. Cell Dev. Biol. 83, 69 (2018).

[11] Kroon H., Huber H., Stuefer J.F. and van Groenendael J.M., A modular concept of phenotypic plasticity in plants, New Phytol. 166(1), 73 (2005).

[12] Zhang X., The epigenetic landscape of plants, Science. 320(5875), 489 (2008).

[13] Kooke R., Johannes F., Wardenaar R., Becker F., EtcheverryM., Colot V., Vreugdenhil D., and Keurentjes J.J.B., Epigenetic basis of morphological variation and phenotypic plasticity in Arabidopsis thaliana, Plant Cell. 27(2), 337 (2015).

[14] Sultan S.E., Organism \& Environment; Ecological Development, Niche Constraction, and Adaptation. Oxford: Oxford University Press, 2015.

[15] Sultan S.E., Phenotypic plasticity in plants: a case study in ecological development, Evol. \& Dev. 5(1), 25 (2003).

[16] Miner B.G., Sultan S.E., Morgan S.G., Padilla D.K. and Relyea R.A., Ecological consequences of phenotypic plasticity, Trends Ecol. Evol. 20(12), 685 (2005).

[17] Mirkin BM. About types of ecologo-cenotic strategies in plants. J. General Biol. 64(6), 603 (1983).(In Russian)

[18] Ramensky L.G., On the fundamental installations, the basic concepts and terms of the production technology of lands, geobotanics and ecology, Soviet Bot. 4, 25 (1935). (In Russian)

[19] Grime J.P., Evidence for the existence of three primary strategies in plants and its relevance to ecological and evolutionary theory, Am. Nat. 111(982), 1169 (1977). 
[20] Grime J.P. and Pierce S., The Evolutionary Strategies that Shape Ecosystems, Chichester: John Wiley \& Sons, 2012.

[21] Romanovsky Yu.E., The current state of the concept of life cycle strategy. Biol. Sci. 11, 18 (1989). (In Russian)

[22] Kordyum E.L., Sytnik K.M., Baranenko V.V., Belyavskaya N.A., Klymchuk D.A. and Neducha O.M., Cell Mechanisms of Plant Adaptation to Adverse Impacts of Ecological Factors in Natural Conditions, Kiev: Naukova dumka, 2003. (in Russian)

[23] Wesselingh R.A., Klinkhamer P., De Jong T. And Boorman L.A., Threshold size for flowering in different habitats: effects of size-dependent growth and survival, Ecology. 78(7), 2118 (1997).

[24] Fargione J. and Tilman D., Competition and Coexistence, Berlin Heidelberg: Springer- Verlag, 2002 , ch. 7, pp. 165-206.

[25] Anisiu M-C., Lotka, Volterra and their model, Didact. Mathem. 32, 9 (2014).

[26] Rabotnov T.A., About types of plant strategy. Ecology. 3, 3 (1985). (In Russian)

[27] Weiner J., Competition among plants, Treballs de la SCB. 44, 99 (1993).

[28] Hutchinson G.E., Homage to santa rosalia or why are there so many kinds of animals?, Am. Nat. 93(870), 145 (1959).

[29] Adler P.B., Smull D., Beard K.H., Choi R.T., Furniss T., Kulmatiski A., Meiners J.M., Tredennick A.T. and Veblen K.E., Competition and coexistence in plant communities: intraspecific competition is stronger than interspecific competition, Ecol. Lett. 21(9), 1319 (2018).

[30] Ellner S.P., Snyder R, E., Adler P.B. and Hooker G., An expanded modern coexistence theory for empirical applications, Ecol. Lett. 22(1), 3 (2019).

[31] Amarasekare P., Competitive coexistence in spatially structured environments: a synthesis, Ecol. Lett. 6(12), 1109 (2003).

[32] Armstrong R.A. and McGehee R., Coexistence of species competing for shared resources, Theor. Popul. Biol. 9, 317 (1976).

[33] Chesson P., General theory of competitive coexistence in spatially-varying environments, Theor. Popul. Biol. 58, 211 (2000).

[34] Hubbell S.P., Neutral theory and the evolution of ecological equivalence, Ecology. 87, 1387 (2006).

[35] Bruno J. F., Stachowicz J. J. and Bertness M. D., Inclusion of facilitation into ecological theory, Trends Ecol. Evol. 18, 119 (2003).

[36] Cardinale B. J., Wright J. P., Cadotte M. W., Carroll I.T., Hector A., Srivastava D.S., Loreau M. and Weis J.J., Impacts of plant diversity on biomass production increase through time because of species complementarity, PNAS. 104(46), 18123 (2007).

[37] Flombaum P. and Sala O.E., Higher effect of plant species diversity on productivity in natural than artificial ecosystems, PNAS. 105(16), 6087 (2008).

[38] Stachowicz J.J., Best R.J., Bracken M.E.S. and Graham M.H., Complementarity in marine biodiversity manipulations: Reconciling divergent evidence from field and mesocosm experiments, PNAS 105(48), 18842 (2008).

[39] Poisot T., Mouquet N. and Gravel D., Trophic complementarity drives the biodiversity-ecosystem functioning relationship in food webs, Ecol. Lett. 16, 853 (2013).

[40] Williams L.J., Paquette A., Cavender-Bares J., Messier C., and Reich B.R., Spatial complementarity in tree crowns explains overyielding in species mixtures, Nature Ecol. Evol. 1, 63 (2017).

Citation: Kordyum E.L., Dubyna D.V., "Phenotypic Plasticity in Plant Adaptation and Coexistence". International Journal of Advanced Research in Botany (IJARB), vol. 5, no. 3, pp. 8-13, 2019. DOI: http://dx.doi.org/10.20431/2455-4316.0503002.

Copyright: (C) 2019 Authors. This is an open-access article distributed under the terms of the Creative Commons Attribution License, which permits unrestricted use, distribution, and reproduction in any medium, provided the original author and source are credited. 